\title{
ASSOCIATION OF MULTIDRUG RESISTANT PULMONARY TUBERCULOSIS AND DIABETES MELLITUS
}

\author{
Sujit Kumar1, Shailendra Kumar Yadav², AD Shukla³, Adesh Singh ${ }^{4}$ \\ ${ }_{1}^{1}$ Associate Professor, Department of Internal Medicine, MLN Medical College, Allahabad, Uttar Pradesh, India. \\ ${ }^{2} 3^{\text {rd }}$ Year Junior Resident, Department of Internal Medicine, MLN Medical College, Allahabad, Uttar Pradesh, India. \\ ${ }_{3}^{3}$ Associate Professor, Department of Respiratory Medicine, MLN Medical College, Allahabad, Uttar Pradesh, India. \\ ${ }^{4}$ Assistant Professor, Department of Internal Medicine, MLN Medical College, Allahabad, Uttar Pradesh, India.
}

\begin{tabular}{l}
\hline ABSTRACT \\
MACKGROUND \\
increases the chances of emergence of resistance in tuberculosis patients. So, the aim of this study is to evaluate the association of \\
diabetes mellitus in the emergence of resistance in tuberculosis patients. \\
Aims and Objectives- To study the association of multidrug resistant pulmonary tuberculosis and diabetes mellitus.
\end{tabular}

Aims and Objectives- To study the association of multidrug resistant pulmonary tuberculosis and diabetes mellitus.

\section{MATERIALS AND METHODS}

218 patients of pulmonary tuberculosis taken in this study who presented to SRN Hospital, over a period of one year from September 2016 to August 2017. Patients were investigated for FBS, PPBS and A1c and Gene-Xpert test was done to find drug resistance among tubercular patients.

Study Design- A cross-sectional observational study.

\section{RESULTS}

Out of 218 patients, 108 were of MDR-TB and 110 were of drug sensitive TB on the basis of Gene-Xpert test. That means, 49.5\% were of MDR-TB and 50.5\% were drug sensitive TB. Out of 108 patients of MDR-TB, 33 (30.60\%) were diabetic and among 110 patients of drug sensitive TB, 19 (17.03\%) were diabetic. After using Chi-square test, p value was found to be 0.0210 which was statistically significant.

\section{CONCLUSION}

Prevalence of diabetes mellitus was higher in patients suffering from tuberculosis and even greater in patients of multi-drug resistant pulmonary tuberculosis, so it can be concluded that diabetes mellitus may be one of the risk factors for emergence of resistance in the patients having pulmonary tuberculosis.

\section{KEY WORDS}

Diabetes Mellitus, Multidrug Resistant Pulmonary Tuberculosis, Gene-Xpert Test.

HOW TO CITE THIS ARTICLE: Kumar S, Yadav SK, Shukla AD, et al. Association of multidrug resistant pulmonary tuberculosis and diabetes mellitus. J. Evolution Med. Dent. Sci. 2018;7(23):2732-2736, DOI: 10.14260/jemds/2018/617

\section{BACKGROUND}

India is the second most populous country in the world and is ranked first among the 22 high burden countries, which accounts for $80 \%$ of all estimated incident cases of TB worldwide. ${ }^{1}$ An important cause of TB epidemic is the emergence of multi-drug resistant (MDR) strains of Mycobacterium tuberculosis. Globally, an estimated 3.3\% of new TB cases and $20 \%$ of previously treated cases have MDRTB (Global Tuberculosis Report 2015). This translates into an estimated 480,000 people having developed MDR-TB in $2014 .{ }^{1}$ If all notified TB patients (6.1 million, new and previously treated) had been tested for drug resistance in 2014, an estimated 300,000 cases of MDR-TB would have been detected, more than half (54\%) of these in three countries alone: India, China and the Russian Federation.

'Financial or Other Competing Interest': None.

Submission 25-04-2018, Peer Review 20-05-2018,

Acceptance 26-05-2018, Published 04-06-2018.

Corresponding Author:

Dr. Shailendra Kumar Yadav,

JR3, P. G. Department of Internal Medicine,

MLN Medical College,

Allahabad,

Uttar Pradesh. India.

E-mail: drskyadav2005@gmail.com

DOI: $10.14260 /$ jemds $/ 2018 / 617$

\section{(c) $(1)(-$}

India, Indonesia and China alone accounted for $23 \%, 10 \%$ and $10 \%$ of total cases, respectively. The Revised National TB Control Program (RNTCP), based on the internationally recommended Directly Observed Treatment Short-course (DOTS $^{2}$ strategy was launched in India in 1997. Data from studies conducted by NIRT and NTI have found MDR-TB levels of less than $1 \%$ to $3 \%$ in new cases and around $12 \%$ in re-treatment cases. Diabetes Mellitus (DM) was a known risk factor for TB in the past, but this was mostly neglected during the second half of the 20th century with the advent of widely available treatment for both diseases. ${ }^{3}$ In recent decades with the increasing prevalence of TB, particularly Multi-Drug Resistant TB and DM cases in the world. The relationship is re-emerging as a significant public health problem. The link of DM and TB is more prominent in developing countries, where TB is endemic, and the prevalence of diabetes is rising. The association between $\mathrm{DM}$ and TB has been known for centuries and in the 1950s the DM patient not dying from a diabetic coma was likely to do so from TB. This association was reduced with the advent of insulin for DM and antibiotics to treat TB, but in the 1980s the co-occurrence began to reemerge as a consequence of the DM 'pandemic' which is predicted to reach 439 million patients by 2030 and is primarily attributed to type $2 \mathrm{DM} .4$ 


\section{Aims and Objectives}

To study the association of multidrug resistant pulmonary tuberculosis and diabetes mellitus.

\section{MATERIALS AND METHODS}

The cross-sectional study was conducted in Moti Lal Nehru Medical College, Allahabad and its associated hospital Swaroop Rani Nehru Hospital from September 2016 to August 2017.

\section{Patients Selection}

Pulmonary TB patients as diagnosed by sputum examination aged > 18 years attending the Medicine and Pulmonary Department (indoor patient and outdoor patient).

\section{Inclusion Criteria}

All individuals aged > 18 years of either sex with MDR pulmonary TB and drug sensitive pulmonary tuberculosis were included in the study.

\section{Exclusion Criteria}

1. Patients with extrapulmonary tuberculosis.

2. Pregnancy.

3. HIV patients.

4. Connective tissue disorder

5. Chronic liver disease.

6. Chronic renal failure.

7. Malignancy.

8. Patients on immunosuppressive therapy.

9. Chronic alcoholics.

\section{Methodology}

The study protocol was explained to all participants and written informed consent was taken in both English and Hindi. Approval for the study was obtained from the Ethics Committee in the institution. All patients were assessed clinically by detailed history taking and general physical examination that included and body mass index also. Height and body weight were measured using a digital scale and body mass index (BMI) was calculated as BMI= body weight (kg)/ height ${ }^{2}$ (metre).

The Study Population was investigated for the following Parameters-

- FPG.

- $\quad$ PPBG.

- $\mathrm{HbA1c}$

\section{CBNAAT- Gene-Xpert Test}

The Gene-Xpert MTB/ RIF assay is a nucleic acid amplification (NAA) test that uses a disposable cartridge with the Gene-Xpert Instrument System. Sputum sample taken for Gene-Xpert test by this resistance was seen for Rifampicin only. And those patients who were resistant for Rifampicin were considered as MDR-TB and patients who were sensitive were considered as drug sensitive TB patients. Venous blood was collected from all patients for FPG, PPBG, HbA1c and the patients who were having FPG $\geq 126 \mathrm{mg} / \mathrm{dL}$ or $\mathrm{PPBG} \geq 200$ $\mathrm{mg} / \mathrm{dL}$ or $\mathrm{HbA} 1 \mathrm{c} \geq 6.5 \%$ were considered as diabetic.

\section{Statistical Analysis}

This study is a cross-sectional observational study. Chisquare test was applied for finding significant association between the categories of variables- that is to find association of MDR-TB and Type 2 DM. Unpaired t-test was applied for finding the significant difference between mean values of variables. SPSS version 19 was used to analyse the data. The numerical data was compared using unpaired t-test for independent variables. The level of significance was considered at $\mathrm{p}<0.05$.

\section{RESULTS}

218 patients of pulmonary tuberculosis were taken in this study who presented to SRN Hospital over a period of one year from September 2016 to August 2017. Out of them 108 were of MDR-TB and 110 were of drug sensitive TB on the basis of Gene-Xpert test. That means $49.5 \%$ were of MDR-TB and $50.5 \%$ were of drug sensitive TB.

Flow Chart showing Status of Drug Resistance and Diabetes

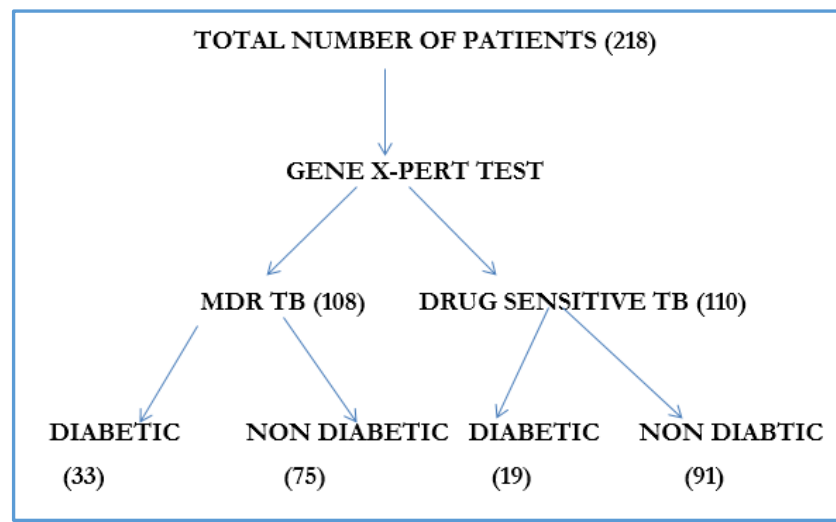

\begin{tabular}{|c|c|c|c|}
\hline Characteristics & $\begin{array}{l}\text { MDR-TB } \\
(n=108)\end{array}$ & $\begin{array}{c}\text { Drug Sensitive } \\
\text { TB }(n=110)\end{array}$ & $\mathbf{P}$ \\
\hline $\begin{array}{l}\text { Mean Age and } \\
\text { S.D. }\end{array}$ & $41.50 \pm 11.91$ & $45.60 \pm 12.99$ & $\mathrm{p}=0.9580$ \\
\hline $\begin{array}{c}\text { Age Group } \\
\text { (30-60 years) }\end{array}$ & 94 (87.04\%) & $72(65.45 \%)$ & $\mathrm{p}=0.0005$ \\
\hline Male patients & $87(80.55 \%)$ & $90(81.81 \%)$ & \multirow[b]{2}{*}{$p=0.867$} \\
\hline Female patients & $21(19.44 \%)$ & $20(18.18 \%)$ & \\
\hline BMI- < & & & \multirow{3}{*}{$\mathrm{p}=0.5543$} \\
\hline $18.5-24.99$ & $10(31 \%)$ & $28(3$ & \\
\hline$>25$ & $2(5 \%)$ & $05(06 \%)$ & \\
\hline FBS & $176.27 \pm 22.40$ & $164.63 \pm 10.00$ & $p=0.037$ \\
\hline PPBS & $230.18 \pm 33.87$ & $205.42 \pm 46.64$ & $\mathrm{p}=0.032$ \\
\hline $\mathrm{HbA1C}$ & $\begin{array}{c}11.1152 \pm \\
1.3271\end{array}$ & $9.6579 \pm 1.7179$ & $p=0.0030$ \\
\hline & $33(30.60 \%)$ & 10 & 0.02 \\
\hline
\end{tabular}

Table 1. Comparison of Characteristics between MDR Tuberculosis and Drug Sensitive Tuberculosis

\begin{tabular}{|c|c|c|}
\hline Patient's Categories & Frequency & Percentage (\%) \\
\hline MDR-TB & 108 & 49.50 \\
\hline Drug Sensitive TB & 110 & 50.50 \\
\hline Total & 218 & 100 \\
\hline \multicolumn{3}{|c|}{$\begin{array}{l}\text { Table 2. Frequency of Patients among MDR-TB and Drug } \\
\text { Sensitive TB }\end{array}$} \\
\hline
\end{tabular}

Mean age for the patients of MDR-TB is $41.50 \pm 11.91$ and for drug sensitive TB is $45.60 \pm 12.99$. 


\begin{tabular}{|c|c|c|c|}
\hline $\begin{array}{c}\text { Patient's } \\
\text { Category }\end{array}$ & $\begin{array}{c}\text { Number of } \\
\text { Patients }\end{array}$ & $\begin{array}{c}\text { Mean Age } \pm \\
\text { S.D. }\end{array}$ & P \\
\hline MDR-TB & 108 & $41.50 \pm 11.91$ & \\
\hline Drug Sensitive TB & 110 & $45.60 \pm 12.99$ & $\mathrm{p}=0.9580$ \\
\hline $\begin{array}{c}\text { Table 3. Mean Age and Standard Deviation of Patients of } \\
\text { MDR-TB and Drug Sensitive TB }\end{array}$ \\
\hline
\end{tabular}

Mean value of FBS in diabetic patients in MDR-TB and drug sensitive TB categories was found to be $176.27 \pm 22.40$ and $164.63 \pm 10.00$ respectively. Both category of patients are having higher values of FBS, which is statistically significant too $(\mathrm{p}=0.037)$.

\begin{tabular}{|c|c|c|c|}
\hline ТВ & $\begin{array}{c}\text { No. of Diabetic } \\
\text { Patients }\end{array}$ & FBS (mg/dL) & $\mathbf{P}$ \\
\hline $\operatorname{MDR}(n=108)$ & 33 & $176.27 \pm 22.40$ & \\
\hline $\begin{array}{c}\text { Drug sensitive } \\
(\mathrm{n}=110)\end{array}$ & 19 & $164.63 \pm 10.00$ & $\mathrm{P}=0.037$ \\
\hline
\end{tabular}

In MDR-TB category 33 patients having FBS in diabetic range and in drug sensitive TB patients 19 patients were having FBS in diabetic range. On application of student t-test, $\mathrm{p}$ value was found to be 0.037 which is statistically significant.

Mean PPBS of diabetic patients in MDR-TB categories was found to be $230.18 \pm 33.87 \mathrm{mg} / \mathrm{dL}$ and in drug sensitive TB categories was $205.42 \pm 46.64 \mathrm{mg} / \mathrm{dL}$. After applying student's t-test, p-value was found to be 0.032 which is statistically significant.

\begin{tabular}{|c|c|c|c|}
\hline TB & $\begin{array}{c}\text { No. of Diabetic } \\
\text { Patients }\end{array}$ & PPBS (mg/dL) & P \\
\hline MDR (n=108) & 33 & $230.18 \pm 33.87$ & \\
\cline { 1 - 3 } $\begin{array}{c}\text { Drug Sensitive } \\
\text { TB (n=110) }\end{array}$ & 19 & $205.42 \pm 46.64$ & $\mathrm{p}=0.032$ \\
\hline \multicolumn{3}{|c|}{ Table 5. PPBS among Diabetic Patients of MDR-TB and } \\
Drug Sensitive TB
\end{tabular}

Diabetic patients among MDR-TB is having higher values of HbA1C than in drug sensitive TB patients. It indicates that the patients of tuberculosis those who have high values of HbA1C may have higher chances of developing MDR-TB. On statistical analysis, data was found to be statistically significant $(p=0.032)$.

\begin{tabular}{|c|c|c|c|}
\hline Patients & Diabetic & HbA1C (Mean) & P \\
\cline { 1 - 3 } MDR-TB (n=108) & 33 & $11.11 \pm 1.3271$ & \multirow{2}{*}{$\mathrm{p}=0.0032$} \\
\cline { 1 - 3 } $\begin{array}{c}\text { Drug Sensitive TB } \\
(\mathrm{n}=110)\end{array}$ & 19 & $9.65 \pm 1.7179$ & $\mathrm{n}$ \\
\cline { 1 - 3 } & &
\end{tabular}

Table 6. HbA1C of Diabetic Patients of MDR-TB and Drug Sensitive TB

Among 108 patients of MDR-TB, 33 (30.60\%) were having diabetes mellitus and 75 were non-diabetic.

\begin{tabular}{|c|c|c|}
\hline DM Status & $\begin{array}{c}\text { No. of MDR-TB } \\
\text { Patients }\end{array}$ & $\begin{array}{c}\text { \% of MDR-TB } \\
\text { Patients }\end{array}$ \\
\hline Diabetic & 33 & $30.60 \%$ \\
\hline Non-Diabetic & 75 & $69.40 \%$ \\
\hline Table 7. Distribution of Diabetes in MDR-TB Patients \\
\hline
\end{tabular}

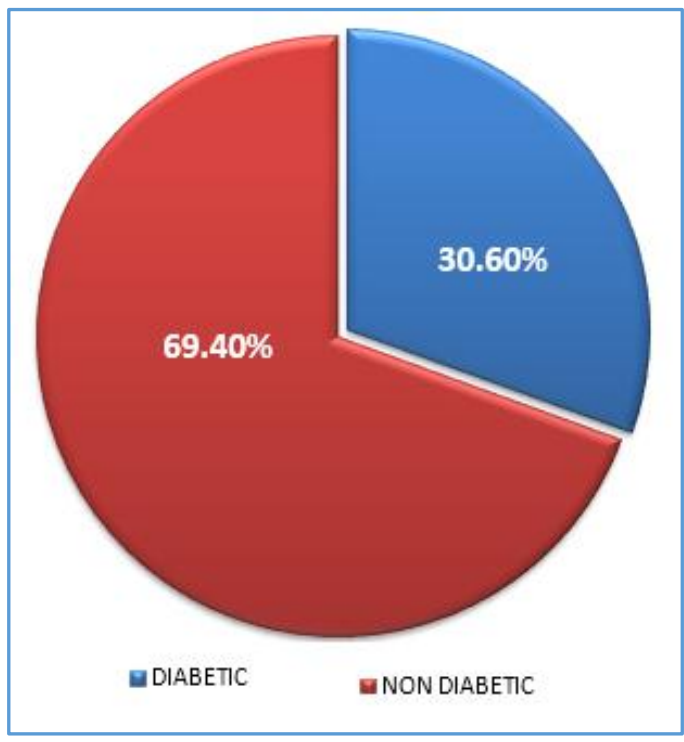

Figure 1. Distribution of DM in MDR-TB Patients

Among 110 drug sensitive TB patients, 19 patients were diabetic, and 91 patients were non-diabetic.

\begin{tabular}{|c|c|c|}
\hline DM Status & $\begin{array}{c}\text { No. of Drug Sensitive } \\
\text { TB Patients }\end{array}$ & $\begin{array}{c}\text { \% of Drug Sensitive } \\
\text { TB Patients }\end{array}$ \\
\hline Diabetic & 19 & $17.30 \%$ \\
\hline Non-Diabetic & 91 & $82.70 \%$ \\
\hline \multicolumn{2}{|c|}{ Table 8. Distribution of DM in Drug Sensitive TB } \\
\hline
\end{tabular}

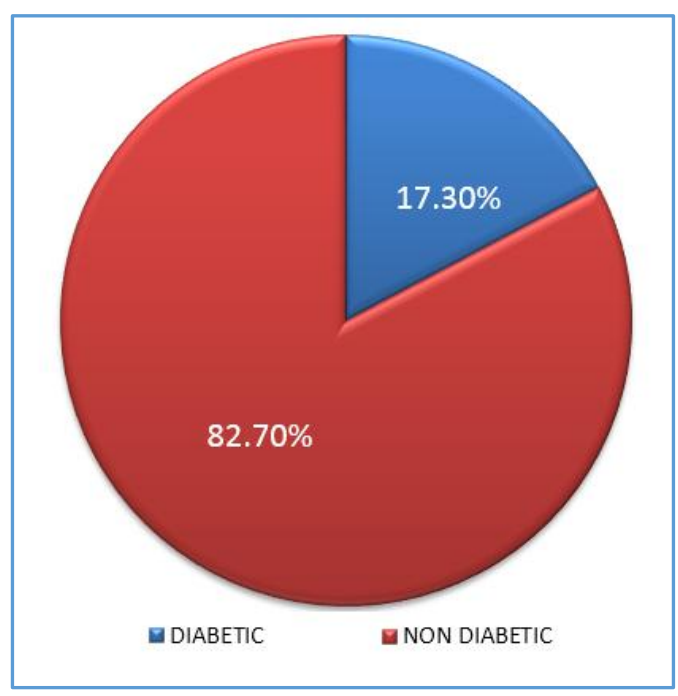

Figure 2. Distribution of DM in Drug Sensitive TB Patients

In this study total patients were 218 and out of 108 patients of MDR-TB $33(30.60 \%)$ were diabetic and in drug sensitive TB categories 19 (17.03\%) were diabetic.

After applying chi-square test, $p$ value was found to be 0.0210 which was statistically significant.

\begin{tabular}{|c|c|c|c|}
\hline $\begin{array}{c}\text { Diabetic } \\
\text { Status }\end{array}$ & $\begin{array}{l}\text { MDR-TB } \\
\text { Patients } \\
(n=108) \\
\end{array}$ & $\begin{array}{l}\text { Drug Sensitive TB } \\
\text { Patients }(n=110)\end{array}$ & $\mathbf{P}$ \\
\hline Diabetic & $33(30.60 \%)$ & $19(17.30 \%)$ & \\
\hline $\begin{array}{c}\text { Non- } \\
\text { Diabetic }\end{array}$ & 75 (69.40\%) & $91(82.70 \%)$ & $\mathrm{p}=0.0210$ \\
\hline
\end{tabular}




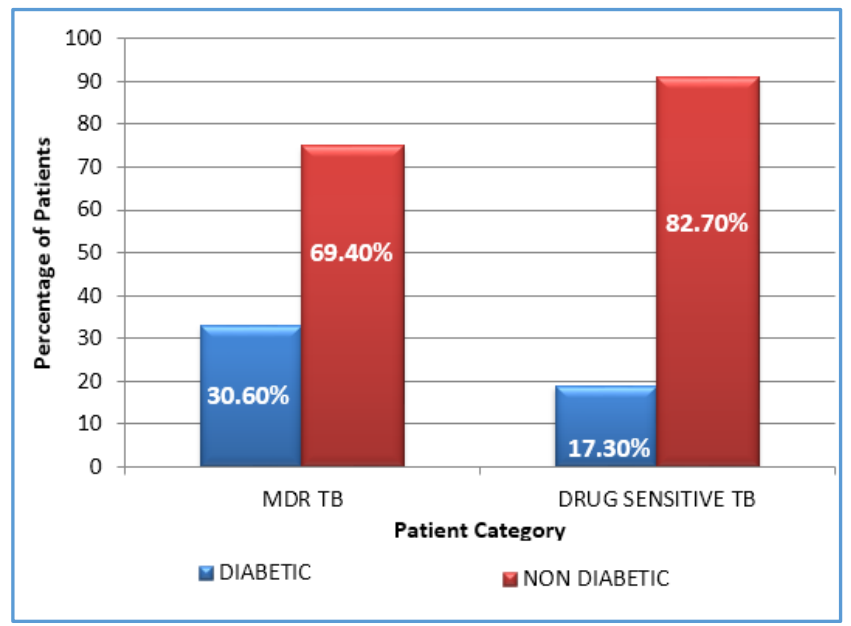

Figure 3. Distribution of Diabetes Mellitus among MDR-TB and Drug Sensitive TB Patients

\section{DISCUSSION}

In this study, 218 patients of PTB were included. On the basis of FPG, PPG and A1C patients were separated into diabetic and non-diabetic group, whereas on the other hand on the basis of CB-NAAT- Gene-Xpert test patients were separated into MDR-TB and drug sensitive TB group. Following were the findings in the study. In this study, the prevalence of diabetes in MDR-TB patients was $30.6 \%$. And in drug sensitive TB, prevalence was $17.03 \%$. A study done by Mohammad Zaeem Khan et al,3 Haryana, India 2017 also found significant association between diabetes mellitus and MDR group ( $\mathrm{p}=.0017)$. In MDR group $45 \%(\mathrm{n}=9)$ had diabetes mellitus, whereas in non-MDR group $14 \%(n=11)$ had diabetes mellitus. In India, the overall prevalence ${ }^{5}$ of diabetes mellitus is $8.7 \%$. Another study done by Keshri Singh Yadav et al $^{6} 2016$ studied- The Pattern of Drug Resistance in Patients of Pulmonary Tuberculosis having Diabetes Mellitus. They found that development of multidrug resistance (MDR) tuberculosis accounted for nearly $37.5 \%$ in diabetics, which was significantly greater in comparison to IGT (33.3\%) and non-diabetics (1.2\%). Saurabh Mehta et al ${ }^{7}$ 2015 studied Rifampin resistance and diabetes mellitus in a cross-sectional study of adult patients in rural South India. Among patients with confirmed TB $(n=194)$, diabetes was associated with 3.0-fold higher risk of rifampin resistance. Another study done by Alejandro Gomez- Gomez et al 2015 found that MDR-TB and DM are associated in 47.2\% of MDRTB cases. Another study done by Baodong Yuan et al ${ }^{9}$ in January 2017 in China on effect of type 2 diabetes mellitus on sputum negative conversion and treatment effects of multidrug-resistant tuberculosis. A total of 359 MDR-TB patients for comparing the sputum negative conversion rates at 2, 6 and 12 months after initiating treatment and the recovery (Treatment Success) rates after completion of treatment for patients with T2DM versus those without T2DM. A total of $20.6 \%$ of the patients (74/359) had T2DM. Guadalupe Delgado-Sánchez et al10 found that $53.87 \%$ patients of MDR-TB have diabetes and $39.03 \%$ were without diabetes. The p-value was $<0.001$, which was significant. Matthew J Magee et al ${ }^{11}$ found that tuberculosis patients who have DM had more cavitation, higher smear positive rates and more MDR-TB as compared to patients without DM (28.1\% vs. $23.6 \%$ ). Another study done by Marta Gomes et $\mathrm{al}^{12}$ found that Diabetes Mellitus, intravenous drug use and previous TB treatment were risk factors for drug-resistant disease development. Another study done by Fengling Mi et $\mathrm{al}^{13}$ found that prevalence of multidrug-resistant TB (MDRTB) was $6.2 \%$ in new patients (N422) and $62.3 \%$ in previously treated patients (N199) with no significant differences between those with and without diabetes. Parvaneh Baghaei et $\mathrm{al}^{14}$ also concluded that TB patients with $\mathrm{DM}$ are at increased risk of anti-TB drug resistance. MariaEugenia Jimenez-Corona et $\mathrm{al}^{15}$ found that the prevalence of DM among 1262 patients with pulmonary TB was $29.63 \%$ $(n=374)$ and patients with DM and pulmonary TB had more severe clinical manifestations. A-H Hsu et al ${ }^{16}$ found that $4 \%$ new TB cases and $15.7 \%$ among previously treated cases in Eastern Taiwan were MDR-TB. Tiyas Sen et al ${ }^{17} 2009$ found that $36 \%$ of the patients with diabetes and TB had MDR-TB, compared to only $10 \%$ in the drug sensitive TB patients. Mona Bashar MD et al ${ }^{18}$ found that $36 \%$ (18 cases) of the patients with diabetes and tuberculosis had multidrugresistant tuberculosis (MDR-TB) compared to only 10\% (10 cases) in the control group ( $\mathrm{p}<0.01)$. A study done by Bokam et al reported $44 \%$ prevalence of diabetes among PTB patients in 2016 . Hardy Kornfeld et al $^{19}$ reported $54.1 \%$ had associated diabetes out of 209 PTB patients from south India in 2016. Park et $\mathrm{al}^{20}$ showed increasing prevalence of TB in DM patients in developing countries like India.

In our study MDR-TB and drug sensitive TB, maximum number of patients were in between 30 and 60 years. In MDR-TB $87.04 \%$ and in drug sensitive TB group $65.45 \%$ patients were in between 30 - 60 years.

A study done by Jagadish Rawat et al,21 which showed the mean age of the patients PTB-DM as $53.3 \pm 14.06$. A study done by Bokam et al, which showed the mean age of the patients PTB-DM as $52.13 \pm 10$. There were more male patients in both the categories. There were $80.55 \%$ in MDRTB categories and $80.81 \%$ males in drug sensitive TB categories and female patients were $19.44 \%$ and $18.18 \%$ respectively. A study done by Bokam et al, which showed $52.3 \%$ were males and remaining $47.7 \%$ were females with mean A1C of 8.5. A study done by Rawat et al, which showed $53.7 \%$ were males and remaining $46.3 \%$ were females. In both categories, patients were having $\mathrm{HbA} 1 \mathrm{C}$ in the higher range. Mean of $\mathrm{HbA1C}$ in MDR-TB DM patients was $10.02 \pm 1.49$ and in drug sensitive TB DM patients mean of $\mathrm{HbA} 1 \mathrm{C}$ was $11.03 \pm 2.12$. A study done by Chen-Yuan Chiang et al,22 which showed $88.8 \%$ had $\mathrm{A} 1 \mathrm{C}$ more than 7 and $11.2 \%$ had A1C less than 7. A study done by Payam Tabarsi et al 23 reported $40 \%$ of their study population had normal glycaemic control of less than 7 .

\section{CONCLUSION}

Diabetes mellitus was more prevalent in patients of multidrug resistant pulmonary tuberculosis, who were having lower body mass index. FPG was more in diabetic patients of multi-drug resistant pulmonary tuberculosis than diabetic patients of drug sensitive pulmonary tuberculosis. PPG was more in diabetic patients of multi-drug resistant pulmonary tuberculosis than diabetic patients of drug sensitive pulmonary tuberculosis. A1c was more in diabetic patients of multi-drug resistant pulmonary tuberculosis than diabetic patients of drug sensitive pulmonary tuberculosis. Prevalence of diabetes mellitus was higher in patients suffering from tuberculosis and even greater in patients of multi-drug 
resistant pulmonary tuberculosis, so it can be concluded that diabetes mellitus may be one of the risk factors for emergence of resistance in the patients having pulmonary tuberculosis.

\section{Limitations of Study}

This study was done in small group of population so cannot be compared with national data. In this study, patients only taken from government hospital, patients attending private health facilities are not included in the study. So, this study is biased. Duration of study was only 1 year, and study was cross-sectional study, so natural history and impact of diabetes cannot be exactly known in this short period of time and in this small study group.

\section{REFERENCES}

[1] WHO global report 2016. Executive summary.

[2] PMDT Guidelines Govt. of India 2012.

[3] Bokam BR, Thota P. Effect of Glycemic control on pulmonary tuberculosis in diabetics. Indian Journal of Basic and Applied Medical Research 2016;5(3):198207.

[4] Khan MZ, Singhal S, Atreja A, et al. Prevalence of MDRtuberculosis in a tertiary care hospital in Haryana. IJCMR 2017;4(1):13-6.

[5] WHO, Global report on diabetes, 2016.

[6] Yadav KS, Singh B, Singh GV, et al. Study the pattern of drug resistance in patients of pulmonary tuberculosis having diabetes mellitus. JAPI 2017;65(1):12-4.

[7] Mehta S, Yu EA, Ahamed SF, et al. Rifampin resistance and diabetes mellitus in a cross-sectional study of adult patients in rural South India. BMC Infectious Diseases 2015;15:451.

[8] Gomez-Gomez A, Magana-Aquino M, Lopez-Meza S, et al. Diabetes and other risk factors for multi-drug resistant tuberculosis in a Mexican population with pulmonary tuberculosis: case control study. Arch Med Res 2015;46(2):142-8.

[9] Yuan B, Du J, Lan X, et al. Effect of type 2 diabetes mellitus on sputum negative conversion and treatment effects of multi- drug-resistant tuberculosis. Biomedical Research 2017;28(9):125-9.

[10] Delgado-Sánchez G, García-García L, Castellanos-Joya $\mathrm{M}$, et al. Association of pulmonary tuberculosis and diabetes in Mexico: Analysis of the National Tuberculosis Registry 2000-2012. PLoS One 2015;10(6):e0129312.
[11] Magee MJ, Kempker RR, Kipiani M, et al. Diabetes mellitus is associated with cavities, smear grade and multidrug-resistant tuberculosis in Georgia. Int J Tuberc Lung Dis 2015;19(6):685-92.

[12] Gomes M, Correia A, Mendonça D, et al. Risk factors for drug-resistant tuberculosis. Journal of Tuberculosis Research 2014;2:111-8.

[13] Mi F, Jiang G, Du J, et al. Is resistance to antituberculosis drugs associated with type 2 diabetes mellitus? A register review in Beijing, China. Global Health Action 2014; 7:24022.

[14] Baghaei P, Marjani M, Javanmard P, et al. Diabetes mellitus and tuberculosis facts and controversies. Journal of Diabetes and Metabolic Disorder 2013;12(1):58.

[15] Jiménez-Corona ME, Cruz-Hervert LP, Garcia-Garcia L, et al. Association of diabetes and tuberculosis: impact on treatment and post-treatment outcomes. Thorax 2013;68(3):214-20.

[16] Reis-Santos B, Gomes T, Horta BL, et al. The outcome of tuberculosis treatment in subjects with chronic kidney disease in Brazil: a multinomial analysis. J Bras Pneumol 2013;39(5):585-94.

[17] Sen T, Joshi SR, Udwadia ZF. Tuberculosis and diabetes mellitus: merging epidemics. The Journal of the Association of Physicians of India 2009;57:399-404.

[18] Bashar M, Alcabes P, Rom WN, et al. Increased incidence of multidrug-resistant tuberculosis in diabetic patients on the Bellevue chest service, 1987 to 1997. Chest 2001;120(5):1514-9.

[19] Kornfeld, West KBS, et al. Diabetes in TB patients from south India: a report from the Effects of Diabetes on Tuberculosis Severity (EDOTS) Study. Chest 2016;02:675. doi:10. 1016/j.chest.

[20] Park SW, Shin JW, Kim JY, et al. The effect of diabetic control status on the clinical features of pulmonary tuberculosis. Eur J Clin Microbiol Infect Dis 2012;31(7):1305-10.

[21] Rawat J, Sindhwani G, Biswas D. Effect of age on presentation with diabetes: comparison of non diabetic patients with new smear-positive pulmonary tuberculosis patients. Lung India 2011;28(3):187-90.

[22] Daniele RP. Immunoglobulin secretion in the airways. Annual Review of Physiology 1990;52:177-95.

[23] Tabarsi P, Baghaei P, Marjani M, et al. Changes in glycosylated haemoglobin and treatment outcomes in patients with tuberculosis in Iran: a cohort study. Journal of Diabetes \& Metab Diaord 2014;13(1):123. 